\title{
NOMADISMO INVOLUNTÁRIO NA REESTRUTURAÇÃO PRODUTIVA DO TRABALHO BANCÁRIO
}

RESUMO

Este artigo trata das conseqüências humanas advindas dos modos de trabal har e de gerir implementados pela reestruturação produtiva do trabalho. Mapeia e analisa a mobilidade - transferências de lugar e/ou de cargo - de sujeitos da reestruturação numa instituição bancária pública; e apresenta as conseqüências da reestruturação a partir da visão dos bancários. 0 estudo de caso foi utilizado como estratégia de pesquisa, cujos dados foram coletados via documentos da empresa, entrevistas informativas e entrevistas semiestruturadas em 1998 e 2003. Os dados sofreram análise estatística e de conteúdo. Os resultados indicam que a reestruturação produtiva acarretou mobilidade de modo diferenciado, e os efeitos mais perversos recaíram sobre sujeitos mais velhos e com mais tempo de serviço, já que estes descenderam na hierarquia da empresa. Como conseqüências humanas, têm-se nomadismo involuntário, instabilidade na estabilidade do emprego, relacionamentos de curto prazo, ruptura dos laços de confiança e sofrimento psíquico.

\section{Carmem Ligia lochins Grisci \\ UFRGS}

\section{Gilles Chemale Cigerza}

UFRGS

\section{Pedro Mendes Hofmeister \\ UFRGS}

João Luiz Becker

UFRGS

\begin{abstract}
ABSIRACT This paper deals with the human consequences caused by modes of working and managing in the restructuring of banking work. It analyzes the mobility - transferences of place and/or position - of employees submitted to restructuring in a public banking institution and presents the consequences of restructuring from the viewpoint of the bank workers. It is a case study, whose data were collected from corporate documents, personal interviews and semi-structured interviews in 1998 and 2003. D ata received statistical and content analysis. Results indicate that the restructuring of banking work caused mobility in different manners. The worst effects were on the senior employees and on those who had more length of service, since they descended in the hierarchy. The main human consequences were the instability in work stability, involuntary nomadism, short-term relationships, break of trust and psychic suffering.
\end{abstract}

PALAVRAS-CHAVE Trabalho bancário, reestruturação produtiva, mobilidade, conseqüências humanas, nomadismo involuntário. KEYWORS Banking work, restructuring work, mobility, human consequences, involuntary nomadism. 


\section{INTRODUÇÃO}

A tual mente as transformações do trabalho redefinem não apenas as modalidades de trabal ho no que dizem respeito à inovação tecnológica, à natureza do desemprego, às relações entre empresas, à mobilidade territorial e social da força de trabalho (Harvey, 1993; Chesnais, 1998; Castells, 1999; Cocco, 2000; Dupas, 2000), mas também os estilos de vida ou modos de subjetivação (Guattari e Rolnik, 1996; Deleuze, 1998). Visando ilustrar como se produzem esses estilos de vida, este artigo discute algumas das transformações e dos sentidos emergentes no mundo desde uma perspectiva de macro-análise.

Bauman (2001) e Sennett (2003) são fontes profícuas ao se referirem, respectivamente, ao labirinto como uma al egoria da condição humana e à corrosão do caráter no novo capitalismo. Para Bauman, o labirinto como sinônimo da compl exidade artificial assume características diferenciadas que dependem das perspectivas espaço-temporais vigentes, e atualmente coloca aos humanos novas exigências para o enfrentamento do que se denomina destino labiríntico. Para compreender 0 enfrentamento e seus efeitos nos sujeitos, mostram-se brevemente algumas das características que compunham a modernidade sólida e seus labirintos sólidos, e al gumas das características que compõem a modernidade líquida e seus labirintos fluidos (Bauman, 2001).

A presente pesquisa visa ampliar o conhecimento sobre os modos de trabal ho e de gestão implementados pela reestruturação produtiva do trabalho bancário e suas conseqüências humanas. Para tanto, mapeia e analisa a mobilidade de sujeitos da reestruturação produtiva do trabalho bancário em uma instituição pública, e verifica as conseqüências humanas dessa reestruturação, de uma perspectiva longitudinal.

Na próxima seção apresenta-se o referencial teórico que privil egiará aspectos referentes à modernidade sólida e à modernidadelíquida, ao nomadismo involuntário no novo capitalismo, ao trabalho imaterial e à subjetividade, e, finalmente, descreve-se a reestruturação produtiva bancária como cenário do estudo desenvolvido. $\mathrm{Na}$ seção seguinte, apresentam-se os procedimentos metodológicos adotados. Em seguida, apresentam-se os resultados e as anál ises. Por fim, apresentam-se as considerações finais.

\section{REFERENCIAL TEÓRICO}

Da modernidade sólida à modernidade líquida

$\mathrm{N}$ a modernidade sólida se identifica 0 amálgama entre capital e trabalho e uma estabilidade relativa. Na modernidade líquida se identifica o anúncio do advento do capitalismo leve e flutuante, com um conseqüente desengajamento e enfraquecimento dos laços que prendem o capital e o trabalho, sob a chancela de uma mentalidade de curto prazo. A modernidade sólida produzia suas novas verdades - seus novos sólidos - a partir da ação restrita de negar as verdades vigentes derreter os sólidos vigentes - para colocá-los em outros moldes igualmente delimitados e rígidos a perpetuarem as certezas acal entadas por meio dessa recorrente reacomodação.

Já a modernidade líquida, numa versão liquefeita, fluida e desregulada da modernidade, apresenta-nos uma moldagem autodeformadora que preserva o controle de uma maneira nova e acarreta a produção de outras subjetividades. Não obstante as instruções claras e os contundentes sinalizadores herdados da modernidade sólida, os sujeitos que hoje habitam a modernidade líquida se tornaram nômades involuntários.

\section{Nomadismo involuntário no novo capitalismo}

Sennett (2003) sustenta a análise relativa à corrosão do caráter tomando como referência o velho e o novo capitalismo. No velho, os sujeitos construíam uma história de vida coerente, amparada em um tempo linear, acumulavam riquezas suficientes para ter uma "vida segura" e se aposentavam com data marcada e salário conhecido. No novo, o tempo é fragmentado, e os sujeitos perdem totalmente o controle não apenas sobre o tempo e o trabal ho como também sobre sua vida. Essa perda de controle é decorrente da idéia de que o longo prazo foi substituído pelo curto prazo. Os sujeitos migram de cidade a cidade, de empresa a empresa, em busca de uma condição melhor, mas não chegando a nenhum lugar: encontram-se à deriva como nômades involuntários.

A flexibilidade exigida no novo capitalismo se sustenta, conforme 0 autor, sobre três pilares: a reinvenção descontínua de instituições, a especialização flexível da produção e a concentração sem centralização. A reinvenção pode ser visualizada nas constantes reengenharias e reestruturações tão em voga atualmente. Consiste numa mudança irreversível, num rompimento com o passado e com o futuro, que torna tudo referente ao aqui e ao agora. As instituições que passam por essas mudanças obtêm, não raro, conseqüências trágicas, como a falência ou processos de demissão em massa, mas aderem a elas na tentativa de provar ao mercado que podem mudar. Decorrente da vo- 
latilidade da demanda do consumidor, a especialização flexível tenta colocar mais rapidamente mais produtos no mercado. Devido à ânsia de responder à demanda com rapidez, as mutações no mundo externo determinam 0 ambiente interno das instituições, fato que colabora para o surgimento da reinvenção descontínua das instituições. Por último, aparentemente uma contradição, a concentração sem centralização diz respeito ao uso de um discurso de distribuição do poder para os níveis mais baixos da hierarquia, mas que de fato o retém. 0 que existe, então, são novas técnicas e tecnologias que propiciam um amplo controle sobre os indivíduos impelidos a essa nova forma de poder na organização desburocratizada, que leva, entre outras conseqüências, ao nomadismo involuntário.

A problemática da gestão contemporânea se colo$\mathrm{ca}$, portanto, nessa lógica geral que enaltece a flexibilidade universal em todos os campos da vida individual, em que o que importa é a interface que se dá entre os diferentes níveis hierárquicos e as diferentes funções e equipes (Cocco, 2000) ou a própria arte de viver no labirinto (Bauman, 2001), e as conseqüências humanas daí decorrentes.

\section{Trabalho imaterial e subjetividade}

Ao trabal ho coube papel fundamental nessa produção de estilos de vida e de modos de subjetivação. Perpassado pelo que se pode denominar tempos mutantes (Grisci, 2003), em contraste com os tempos modernos forjados pela modernidade, o trabalho pós-industrial, ou 0 da modernidade líquida ou o da pós-modernidade, ou do novo capitalismo, conforme denominações propostas por autores como Harvey (1993), Cocco (2000), Bauman (2001) e Sennett (2003), produz um outro sujeito. Um sujeito que habita a velocidade, como diz Virilio (1996), já que o tempo se dilui a olhos vistos. Tal sujeito se encontra diante do que Lazzarato e Negri (2001) tomam por trabalho imaterial.

Por trabalho imaterial, Lazzarato e Negri (2001) entendem aquele que, além de produzir objetos concretos, produz informação, conhecimento, serviços e valores. E que se define como imaterial porque incide sobre algo imaterial, que é a subjetividade humana. Isso leva o trabal hador do imaterial a caracterizar-se pela contínua inovação das dinâmicas de produção. Para esse sujeito, os roteiros previamente traçados, as instruções claras e os sinalizadores herdados da modernidade sólida já não atendem às novas demandas.
Em face do trabalho imaterial se encontram novas teorias e práticas de gestão, já que o modo de trabal ho capitalista de hoje requer de quem trabal ha habilidades como iniciativa, mobilidade, cooperação, domínio do processo, entre outras. Embora tais características possam se mostrar efêmeras e contingenciais, sua disponibilização depende do investimento pessoal no trabal ho. Diante disso, "a condição do trabalho imaterial é a produção de subjetividade, o conteúdo do trabalho imaterial é a produção de subjetividade, o resultado do trabalho imaterial é a produção de subjetividade. Ou seja, a produção de subjetividade atravessa tanto o processo de trabal ho quanto o seu produto" (Pelbart, 2000, p. 37).

\section{Reestruturação produtiva bancária}

A reestruturação produtiva concretiza as teorias e práticas de gestão do novo capital ismo, evidenciando-se como um espaço privilegiado da apropriação do trabalho imaterial que define modos de existência dos trabal hadores.

A partir da desregulamentação e dos avanços da tecnologia de informação, em particular, empresas de diferentes setores sofreram transformações si gnificativas, tanto tecnológicas como de gestão, bem como em relação à competição que travam entre si. Com a necessidade incessante de se adaptarem ao mundo globalizado, as empresas passaram a investir para o alcance de maior velocidade e flexibilidade, buscando tornar-se indiferentes às restrições de tempo, espaço e moeda.

O setor bancário, onde o processo de informatização e os recursos da sociedade da informação se tornaram mais presentes, pode ser tomado como de vanguarda e paradigmático dessas transformações. Inscrito nesse movimento de reestruturação que torna as frontei ras cada vez mais permeáveis, o setor bancário indica a criação de uma nova ordem do processo do trabal ho intrinsecamente relacionada às inovações tecnológicas e mudanças organizacionais. Essas inovações e mu danças se mostraram voltadas à maximização dos recursos disponíveis e ao aumento da produtividade humana, demandando requalificações dos sujeitos bancários. Novos conhecimentos e novos modos de ser deveriam ser incorporados num ritmo de trabalho caracterizado por uma velocidade até então inimaginável (Grisci, 2003).

Verifica-se, então, que o trabal ho bancário se reestrutura ao longo das últimas décadas em suas formas de organização e execução. Com a tecnologia da informação, acoplaram-se maior mobilidade e maior complexidade aos modos de trabalho bancário. Os 
papéis e documentos bancários foram, em larga escala, substituídos por dados armazenados e manipulados em sistemas el etrônicos. A incorporação acirrada das novas tecnologias desencadeou demissões em massa, o que nos bancos públicos se deu por meio dos Programas de Apoio à Demissão Voluntária (PADV) (Bessi e Grisci, 2003). Àquel es que permaneceram trabalhando, outros modos de existência individuais e col etivos foram solicitados. Tais modos resultaram dos perfis que dizem da flexibilidade, adaptabilidade, cultura de desconstrução e reconstrução, e do processamento instantâneo de novos valores.

A partir da problemática teórica e empírica considerada, a questão de pesquisa é a seguinte: como se caracteriza a mobilidade dos sujeitos da reestruturação produtiva do trabalho bancário e quais as conseqüências humanas dela decorrentes? Entendendo-se mobilidade como as transferências de cargo ou de lugar que sofrem os sujeitos, respondeu-se a essa questão por meio de uma pesquisa de caráter longitudinal numa centenária instituição financeira pública, de grande porte e abrangência nacional, doravante denominada empresa $X$. Atualmente, a empresa $X$ possui 1.950 agências e aproximadamente 60 mil funcionários; implantou diversos programas relativos à reestruturação produtiva a partir de 1995, e apresentou mudanças em sua área de atuação, buscando competitividade no mercado por meio da segmentação de clientes.

Com esta pesquisa busca-se ampliar o conhecimento acerca das conseqüências humanas advindas dos modos de trabalho e de gestão implementados pela reestruturação produtiva do trabalho. As próximas seções terão por objetivo (a) mapear e analisar a mobilidade dos sujeitos da reestruturação produtiva do trabal ho bancário e (b) verificar as conseqüências da reestruturação produtiva do trabalho bancário.

\section{PROCEDIMENTOS METODOLÓGICOS}

\section{Estratégia da pesquisa}

Trata-se de um estudo longitudinal que contempla os acontecimentos relativos à reestruturação produtiva do trabalho bancário e, em especial, à mobilidade dos sujeitos no período de 1990-2003 no contexto de uma única empresa. Caracteriza-se como um estudo de caso (Yin, 2001), e corrobora a afirmação de Roesch (1998) de que uma das vantagens de um estudo de caso é a possibilidade de examinar os acontecimentos ao lon- go do tempo e compreender as mudanças ocorridas nos padrões de vida e no cotidiano, podendo o estudo original vir a ser continuado anos depois.

\section{Sujeitos da pesquisa}

A pesquisa contou com um total de 44 bancários, entrevistados inicial mente em 1998, escolhidos por conveniência de acesso, quando a reestruturação produtiva se mostrou visível em termos de estrutura física e de automatização. Atual mente esse número corresponde a $9,26 \%$ do total de bancários que fazem parte do Escritório de N egócios N orte da empresa, em Porto Alegre, no Rio Grande do Sul. Dados quantitativos de 35 desses 44 bancários integraram a totalidade da parte quantitativa da pesquisa, uma vez que nove saíram da empresa entre 1998 e 2003 por motivos de aposentadoria, adesão ao PADV ou rescisão a pedido. Dados qualitativos de cinco desses 35 bancários (entrevistados novamente em 2003) integraram a parte qualitativa da pesquisa. No que diz respeito a gênero, idade, tempo de serviço e mobilidade, os sujeitos da pesquisa se caracterizam conforme a $\mathrm{Fi}$ gura 1.

\section{Coleta de dados}

A coleta de dados foi feita por meio de entrevistas semiestruturadas, entrevistas informativas e fontes documentais. Cinco dos 44 bancários entrevistados em 1998 foram novamente entrevistados em 2003, perfazendo um total de 10 entrevistas semi-estruturadas. Houve dificuldade de entrevistar um número maior de sujeitos em 2003, pela própria mobilidade que inviabilizou 0 acesso a eles. Assim, as entrevistas seguiram o critério de acessibilidade e disponibilidade. Com a permissão dos entrevistados, elas foram gravadas, sendo posteriormente transcritas. A coleta de dados contou ainda com entrevistas informativas realizadas com dois anal istas da área de Recursos H umanos, que disponibilizaram documentação e informações referentes à mobilidade e à classificação dos cargos dos sujeitos, bem como às diversas etapas da reestruturação produtiva na empresa $X$. As fontes documentais consistiram em prospectos, instruções normativas, jornais internos, jornais da associação de pessoal da empresa, e documentos relativos à progressão funcional e à mobilidade de lugar dos bancários. Estes últimos foram utilizados para coletar os dados utilizados na parte quantitativa do estudo, e para estabel ecer os recortes temporais estabelecidos nas análises de regressão realizadas. 


\section{Análise dos dados}

Os dados quantitativos sofreram tratamento estatístico e os qualitativos, análise de conteúdo. Tendo em vista o longo período de tempo anal isado, e em razão de o processo de reestruturação ter modificado diversas vezes a estrutura hierárquica e a natureza dos cargos, fez-se necessário agrupá-los em níveis ordenados de acordo com os seguintes critérios: hierarquia, prestígio, complexidade das atribuições e equival ência saIarial. Tal procedimento teve validação de conteúdo por dois analistas de Recursos Humanos da empresa X. O Q uadro 1 apresenta os sete grupos de cargos aos quais pertenceram ou pertencem os sujeitos.

Para proceder à anál ise quantitativa e possibilitar a comparação entre os agrupamentos dos sujeitos por tempo de serviço, idade e gênero, construiu-se um índice que mostra o comportamento da variável grupo de cargos, de acordo com a classificação apresentada no Quadro 1. Participaram da formação do índice os 44 sujeitos, sendo que cada suj eito passou a integrar 0 cálculo do índice quando assumiu o cargo anterior à sua primeira transferência (de cargo ou de lugar) de-

Figura 1 - Caracterização dos sujeitos.

Figura 1a: Distribuição dos sujeitos por gênero

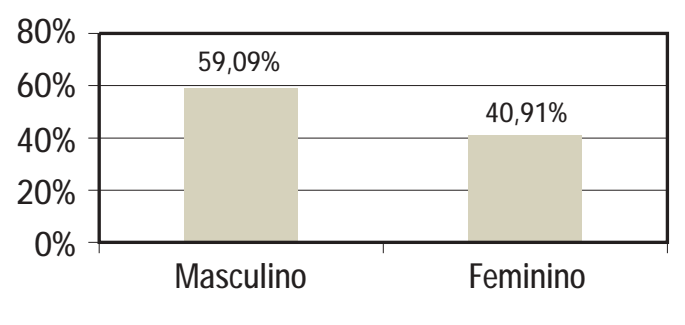

$\%$ dos sujeitos

Figura 1c: Distribuição dos sujeitos por tempo de serviço na empresa $X$

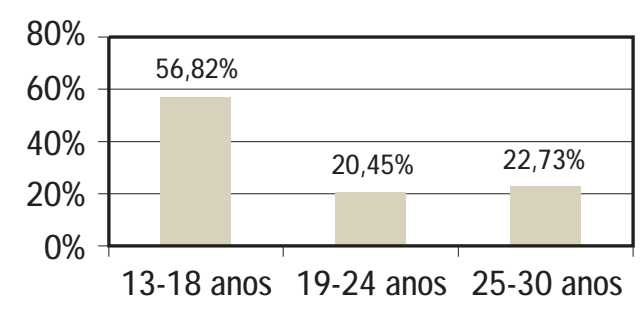

$\%$ dos sujeitos pois de 1־/01/1990. Os nove sujeitos que saíram da empresa, por motivo de aposentadoria, rescisão a pedido ou adesão ao PADV deixaram de participar do cálculo do índice no dia seguinte ao da sua saída.

0 índice é o cargo médio de um grupo de sujeitos em numa certa data $\left(\right.$ CM Sgrupo $\left._{t}\right)$. Ele é cal culado pelo somatório dos grupos de cargo que os sujeitos ocupam em determinada data t dividido pelo número de sujeitos, conforme a fórmula:

$$
\text { CMSgrupo }_{t}=\frac{\sum_{i=1}^{n} C_{i}}{n}
$$

$C_{i}$ : grupo de cargo que o sujeito i ocupa na data t; n: número de sujeitos do grupo que estão participando do cál culo do índice.

Esse índice aparecerá na análise e apresentação dos resultados (veja Figuras 3, 4 e 5). Posteriormente à elaboração do índice, os dados quantitativos sofreram tratamento estatístico por meio de três análises de re-
Figura 1b: Distribuição dos sujeitos por idade

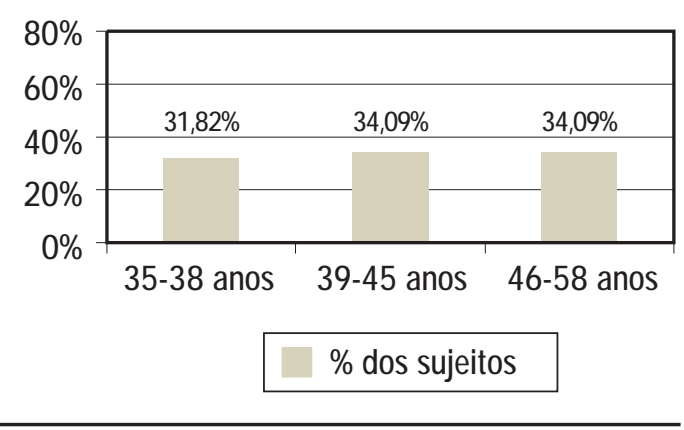

Figura 1d: Mobilidade para fora da empresa $X$

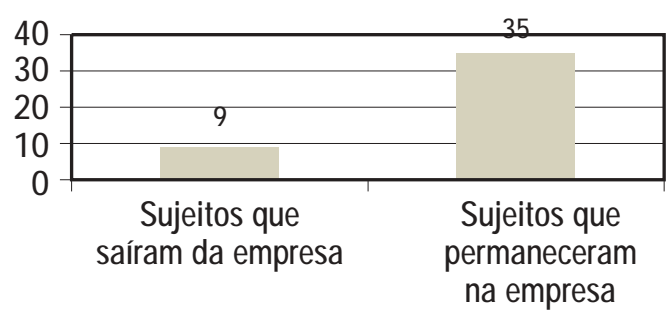

número de sujeitos 
gressão linear múltipla (método stepwise) com auxílio do software SPSS for Windows. As variáveis independentes consideradas incluíram idade, gênero (variável binária, com valores 0 ou 1), tempo de serviço e quantidade de transferências de lugar de cada sujeito. A variável dependente foi o grupo de cargos. As análises de regressão objetivaram verificar a influência da variabilidade das variáveis independentes sobre a variabilidade do grupo de cargos dos sujeitos antes e no decorrer da reestruturação produtiva. Em relação às transferências de lugar, estabel eceram-se recortes temporais em 1995, 1997, 2000 e 2003, contemplando-se tanto o início da reestruturação produtiva como os programas subseqüentes mais significativos implantados em consonância com ela. Embora a reestruturação produtiva tenha se iniciado na empresa em 1995, os dados utilizados, apresentados nos resultados da pesquisa, remontam ao início da década de 1990, visando comparar a mobilidade dos sujeitos antes da reestruturação e no seu decorrer.

A análise dos dados provenientes das entrevistas semi-estruturadas e das fontes documentais priorizou o entendimento qualitativo da realidade social à luz da literatura pertinente, por meio de categorias de cunho coletivo, conforme orientações de Minayo (1994). Procedeu-se, seqüencialmente, a uma pré-análise do material, que permitiu a definição das unidades de sentido; a uma exploração do material, com mapeamento dos temas emergentes que possibilitaram, a partir dos objetivos da pesquisa, a categorização dos dados; e por último, à interpretação dos dados à luz da teoria. Cabe salientar que a interpretação é feita por meio da síntese, construção criativa de significados, e, sendo um processo contínuo e infinito, poderá vir a ser ampliada ao longo do tempo.

\section{ANÁLISE DOS RESULTADOS}

\section{Breve panorama da reestruturação produtiva do trabalho na empresa $X$}

A reestruturação produtiva teve na queda da inflação um desencadeador importante, e pode ser tomada como um processo que ocorreu em duas etapas: reestruturação para dentro e para fora (Dieese, 2001). No caso do setor bancário brasileiro, a reestruturação para dentro se iniciou ainda em período de altas taxas inflacionárias, em especial a partir da segunda metade da década de 1980, sendo fortemente influenciada pelos avanços na tecnologia da informação, enquanto a reestruturação para fora coincide com a queda da inflação, ocorrida a partir da segunda metade da década de 1990. A reestruturação para dentro acarretou a incorporação de novas tecnologias e desencadeou demissões em massa, que nos bancos públicos ocorreram por meio dos PADVs. A segunda etapa de reestruturação (para fora) deu-se, em especial, por meio de processos que envolveram transferência de controle acionário, intervenção ou liquidação por parte do Banco Central, e incorporação por outra instituição financeira. Ao final da década de 1990, a grande inserção de bancos internacionais foi outro processo que se somou aos aj ustes para fora (Dieese, 2001).

$\mathrm{Na}$ empresa $\mathrm{X}$, a reestruturação produtiva ocorreu mais tardiamente, sendo seu início marcado por algumas medidas tomadas no princípio da década de 1990 para resolver a "mais profunda crise de sua história", conforme atestam documentos da empresa referentes à época. A partir de então, inúmeros programas se fizeram notar como parte do processo de reestruturação da empresa. Na Figura 2 estão dispostos em uma linha de tempo al guns desses programas. Todos serão

Quadro 1 - Grupos de cargos.

GRUPO

0

1 Caixa Executivo, Tesoureiro de Retaguarda, Secretário, Avaliador e Avaliador Executivo

2 Assistente Administrativo, Agente Empresarial, Secretário de Superintendência Regional, Auxiliar de Mercado, Auxiliar de Supervisão, Assistente de Operações, Técnico de Retaguarda, Técnico de Fomento, Técnico de Nível Médio

3 Assistente Geral, Supervisor, Supervisor de Habitação, Supervisor de Retaguarda, Assistente de Superintendência Regional

4 Gerente, Gerente de Atendimento, Gerente de Relacionamento, Supervisor de Logística, Gerente Adjunto, Analista Sênior, Gerente de Núcleo, Gerente de Negócios

5 Gerente Geral, Gerente de Filial

6 Gerente Operacional, Gerente de Mercado 
brevemente descritos, e aqueles diretamente relacionados à mobilidade, como o Programa de Racionalização e Competitividade (PRC) e o Modelo de Segmentação de Clientes, merecerão maior atenção.

Estabelecido em 1993, o programa A Empresa X em Primeiro Lugar pode ser considerado como um sinalizador das mudanças vindouras. Foi implantado em uma crise não só econômico-financeira como também operacional e tecnológica. Ele já começava, embora suavemente, a exigir maior flexibilidade ea impor maior competitividade ao corpo gerencial da empresa. Flexibilidade e competitividade essas que seriam acentuadas por medi das subseqüentes. Também naquele ano foi iniciado o Programa de Qualidade Total, que buscava cristalizar os objetivos da empresa de maneira que todos "vestissem a camiseta", formando uma massa homogênea com objetivos comuns.

Em 1995, o PRC transformou definitivamente os modos de ser e trabalhar até então vigentes na empresa. Chamado de reengenharia pelos funcionários, o PRC possibilitava, segundo a empresa, uma estrutura organizacional mais ágil e funcional por promover a descentralização administrativa. Devido ao seu impacto sobre a organização e sobre os sujeitos, esse programa pode ser considerado um marco da reestruturação produtiva. Em decorrência dele ocorreu um processo seletivo interno para cargos gerenciais, ao qual os gerentes da empresa tiveram que se submeter. Como resultado do processo seletivo, muitos gerentes perderam suas funções gratificadas, o que não ocorreu sem sofrimento psíquico. Conforme os resgates possibilitados pela memória, tem-se a alusão de que, segundo um dos entrevistados, "pessoal com 25 anos de empresa não passou no processo seletivo, tendo que retornar à posição de escriturário, o que acarretou, inclusive, afastamentos por licença de saúde". 0 reflexo dessas medidas foi entendido como sendo significativo, e alguns desses gerentes foram aproveitados na função de gerentes em locais de trabal ho diferentes de seus locais originais. 0 programa também incluía a automação das agências e 0

Figura 2 - A reestruturação produtiva como cenário à mobilidade: um breve histórico.

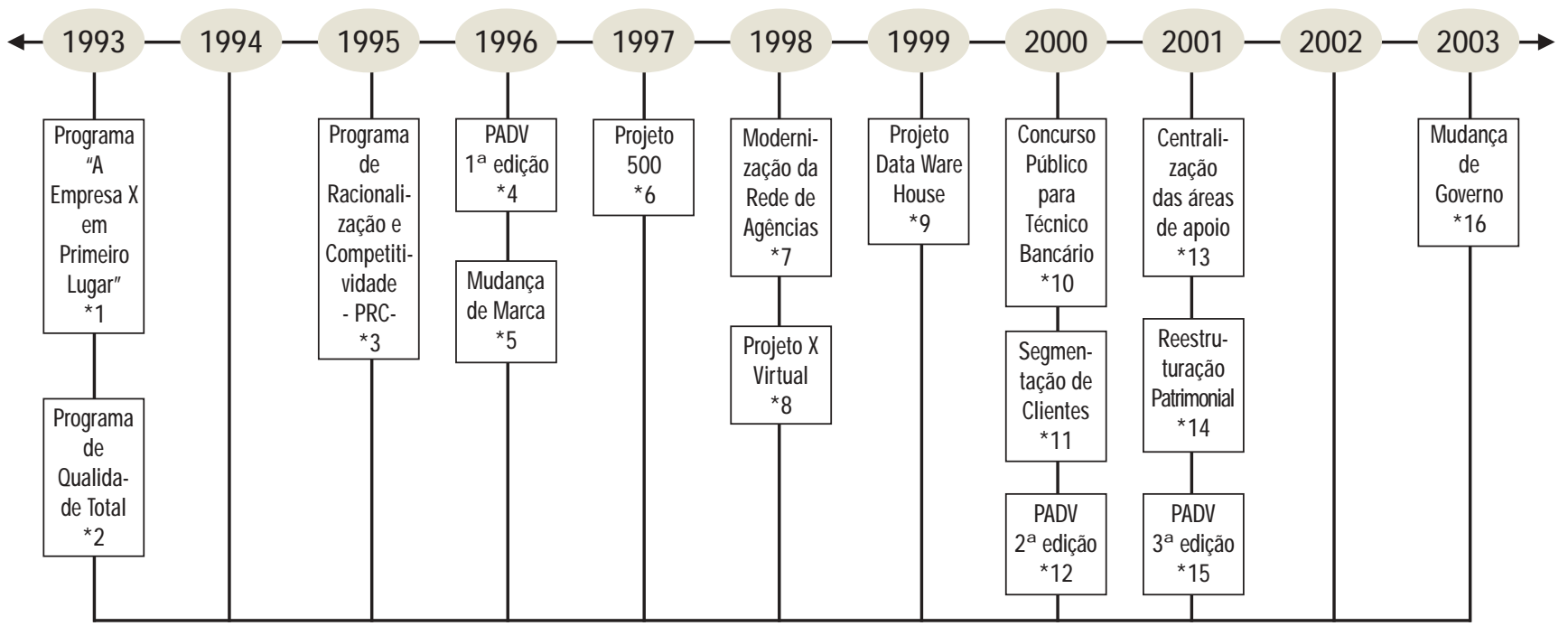

Fonte: Documentos da empresa.

$\begin{array}{lc}* 1 \text { - Competitividade e flexibilidade relacionadas ao corpo gerencial da empresa. } & * 9 \text { - Fornecimento de informações à gestão empresarial e ampliação de terminais de } \\ * 2 \text { - Padronização e disseminação dos objetivos da empresa. } & \text { auto-atendimento. } \\ * 3 \text { - Transformação da estrutura hierárquica. } & * 10 \text { - Contratação de novos funcionários. } \\ * 4 \text { - Programa de Apoio à Demissão Voluntária, que visou à redução do número de } & * 11 \text { - Modelo de gestão de clientes que os segmenta em carteiras específicas. } \\ \quad \text { funcionários. } & * 12 \text { - Programa de Apoio à Demissão Voluntária, que visou à redução da curva } \\ \text { *5 - Modernização do logotipo. } & \text { salarial. } \\ * 6 \text { - Automatização e modernização das } 500 \text { maiores agências da empresa no } & * 13 \text { - Centralização das áreas de apoio em Brasília-DF e extinção das filiais regionais. } \\ \quad \text { país. } & * 14 \text { - Adaptação da empresa ao Acordo de Basiléia, incluindo separação de passivos. } \\ * 7 \text { - Automatização e modernização do restante das agências. } & * 15 \text { - Redução da curva salarial; aderiram aproximadamente } 2.800 \text { bancários nesta edição. } \\ * 8 \text { - Utilização da Internet como ponto-de-venda. } & * 16 \text { - Retorno à função social exercida pela empresa Xanteriormente. }\end{array}$


direcionamento da empresa para atender ao mercado e competir com os bancos privados, para se configurar cada vez mais como um banco múltiplo (Dieese, 2001).

No ano seguinte ocorreu a primeira edição do PADV, ao qual aderiram cerca de 3.700 funcionários. Segundo a empresa, o PADV forneceu uma chance de desligamento com vantagens adicionais e foi um dos fatores fundamentais para o enquadramento dos funcionários ao novo modelo de gestão implementado pelo PRC. Nesse mesmo ano a marca também foi mudada, sendo o antigo logotipo substituído por uma marca mais moderna.

No ano de 1997 foi iniciada a Modernização da Rede de Agências, por meio do Projeto 500, que consistiu na modernização das 500 maiores agências da empresa no Brasil. Tal modernização foi concluída em 1998, quando todas as agências foram modernizadas. Essa mudança representou o lado "visível" das transformações que vinham acontecendo continuamente na empresa. Cabe ressaltar que, embora o PRC tenha sido um dos propulsores da mobilidade, coube à modernização dar a característica de instantaneidade às mudanças. Em 1999 foi implantado o Projeto Data Warehouse, visando o fornecimento de informações à gestão empresarial, e a ampliação do número de terminais de auto-atendimento.

Em 2000 foi institucionalizado o Modelo de Segmentação de Clientes, que possibilitava a gestão da massa de clientes categorizando-os em níveis de relacionamento, a fim de que lhes fossem dispensados tratamentos diferenciados, transformando-os em público-alvo a partir de suas faixas de rendimentos. A segmentação acarretou tratamentos diferenciados, ofertas de produtos e de serviços específicos, e distinta disponibilidade de tempo, atenção e privacidade. Seus principais objetivos eram estruturar diferentes níveis de relacionamento, de acordo com o poder de compra dos clientes; e melhor alocar os recursos da empresa, aumentando a rentabilidade por cliente.

0 modelo de segmentação implicou uma nova reestruturação da empresa como um todo. A partir dele, os pontos-de-venda foram reestruturados, no que se refere aos aspectos físicos, tecnológicos e ao pessoal. A partir das ações exigidas pelo modelo, a estrutura gerencial dos pontos-de-venda se alterou para atender às diferentes carteiras de clientes. Para tanto, ocorreu a designação de novos gerentes. Entraram em cena os gerentes de atendimento, voltados para o segmento básico, e os de relacionamento, voltados para as outras carteiras de clientes. A segmentação de clientes levou, nesse sentido, à segmentação do corpo gerencial. E as ações gerenciais passaram, então, a ser balizadas por diretrizes de atuação do tipo: tempo (horas/ano) que cada gerente deve despender para cada tipo de segmento de clientes, número mínimo de contatos anuais que o gerente deve manter com cada tipo de cliente e nova descrição dos cargos gerenciais, com suas alterações de funções, entre outros.

Os novos modos de trabalhar advindos desse modelo atingiram todos os bancários. Como comentam alguns: "Hoje já faz parte do dia-a-dia de todos os empregados, de todos os colegas, que é necessário atingir metas, que as metas têm que ser cumpridas, que têm que ser cumpridas $100 \%$ das metas". As metas eram ousadas, como demonstram documentos da empresa, que apresentam o percentual de clientes que um dado produto deveria atingir em um prazo estipulado. Como já é possível notar, esse modelo teve implicações na questão da mobilidade dos sujeitos.

Também em 2000 houve concurso público para técnico bancário, e a segunda edição do PADV. O concurso objetivou a contratação de novos funcionários sob um regime diferenciado de salários, sem bonificações, sem aumentos por tempo de serviço e com salários mais baixos. A segunda edição do PADV visou diminuir a curva salarial da empresa, sendo direcionada aos funcionários com maiores salários, ou seja, os mais antigos na empresa.

No ano de 2001 foi iniciada a centralização das áreas de apoio, tais como logística, recursos humanos e suprimentos em Brasília, visando a extinção das filiais regionais. Como o volume de trabal ho se mostrou excessivo em Brasília, houve a manutenção das três maiores filiais em distintos estados, que passaram a funcionar com um número reduzido de funcionários. N este ano, para adaptar-se ao Acordo de Basiléia, a empresa fez uma reestruturação patrimonial. Em 2001 foi lançada outra edição do PADV, que, semel hantemente à edição anterior, objetivou a redução da curva salarial, acarretando a adesão de cerca de 2.800 funcionários. Com a mudança do governo federal em 2003, a política de gestão da empresa voltou a enaltecer a função social da empresa.

Como se pode notar, a partir de 1993 as mudanças se tornaram uma constante na empresa. Em especial com o PRC e a segmentação de clientes, a mobilidade se tornou mais freqü ente e adquiriu características até então inexistentes, como se analisará a seguir.

\section{Mapeamento da mobilidade}

No período anterior ao PRC, quando a reestruturação ainda não se fazia notar, havia maior estabilidade das 
pessoas nos cargos e lugares. Com a reestruturação produtiva, aumentou a mobilidade dos sujeitos, tanto no que se refere às transferências de lugar quanto às de cargo.

Os motivos que levam à mobilidade a caracterizam como ascendente, descendente ou oscilante. A mobilidade é classificada como ascendente quando o sujeito passa a ocupar sucessivamente grupos de cargo superiores aos anteriormente ocupados, sendo motivada por vantagem financeira ou reconhecimento profissional ao longo da trajetória do sujeito na empresa. Durante a segmentação de clientes, esse tipo de mobilidade foi expressivo, devido ao aumento do número de cargos gerenciais. A tualmente ocorre por intermédio do banco de oportunidades, que busca al inhar os interesses dos funcionários aos interesses da empresa.

A mobilidade é classificada como descendente quando o sujeito passa a ocupar sucessivamente grupos de cargo inferiores aos anteriormente ocupados. Em geral advém do não atingimento de metas continuamente crescentes, quando os sujeitos não se adaptam ao perfil exigido para o cargo, ou não suportam a cobrança e a pressão. Pode ocorrer ainda por mudanças estratégicas ou estruturais provenientes dos novos modos de gestão. Com a implantação do PRC, esse tipo de mobilidade foi expressivo devido ao processo sel etivo, que fez com que muitos gerentes perdessem seus cargos.

A mobilidade é classificada como oscilante quando, ao longo da vida profissional na empresa, o sujeito ora ascende, ora descende na estrutura hierárquica, ora é transferido de lugar sem que ocorram mudanças relativas ao cargo. Esse tipo de mobilidade se relaciona com a desconstrução dos vínculos dos grupos informais constituídos ao longo do tempo como estratégia de facilitação à implementação de novos modos de gestão. Relaciona-se também com o ajuste da quantidade de pessoal devido às mudanças estruturais em termos de número e tamanho de agências, e com a satisfação das preferências pessoais dos funcionários, caso isso não represente nenhum prejuízo para a empresa.

Para evidenciar como a reestruturação produtiva influenciou na mobilidade dos sujeitos, procederamse a algumas análises de regressão linear múltipla envolvendo as variáveis: gênero, idade, tempo de serviço, mobilidade e cargo ocupado em 1995 e em 2003.

A primeira anál ise de regressão se refere ao período anterior ao PRC implantado em 1995, e objetivou identificar o que mais influenciava a ocupação de grupos de cargos posicionados na estrutura hierárquica naquela época. N essa primeira regressão, a variável de- pendente é o cargo dos sujeitos em 1995 (cargo em 95), de acordo com a classificação dos grupos de cargos apresentada anteriormente, e as variáveis independentes são o gênero (gênero), a idade (idade) e o tempo de serviço na instituição (tempo de serviço). Com essa regressão ( $R^{2}$ aj ustado $=0,277$; $A N$ OVA: $F=7,516$, $g l=34, p=0,002$ ), evidencia-se que, em 1995, a variabilidade no tempo de serviço (beta $=0,453$ ) era o fator mais importante para explicar a variabilidade nos cargos ocupados pel os sujeitos. Tem-se que a melhor ocupação de cargos até 1995 correspondia aos sujeitos com maior tempo de serviço na empresa ou aos antigos, conforme eles próprios se denominam. 0 gênero (beta $=0,365$ ) também explicava a variabilidade nos cargos ocupados pelos sujeitos, encontrando-se os homens mais bem posicionados na estrutura hierárquica da empresa do que as mulheres. Idade é fortemente correlacionada com tempo de serviço $(r=0,933)$, e o método stepwise a excluiu da análise, não havendo explicação adicional significativa para a variabilidade nos cargos ocupados pelos sujeitos em 1995.

A segunda análise de regressão se refere ao ano de 2003, quando a reestruturação produtiva já havia se consolidado, e objetivou identificar o que passou a influenciar a ocupação de grupos de cargos posicionados na estrutura hierárquica. Nessa regressão, a variável dependente é o cargo dos sujeitos em 2003 (cargo em 2003), com as mesmas variáveis independentes. Os resultados $\left(R^{2}\right.$ ajustado $=0,170$; ANOVA: $F=4,486, g l=34, p=0,019)$, evidenciam que, com a consolidação da reestruturação produtiva, no ano de 2003, o gênero continua explicando significativamente ( beta $=0,332$ ) a variabilidade nos cargos ocupados pelos sujeitos, embora com menor intensidade do que em 1995 (beta $=0,365$ ). Os homens continuam mais bem posicionados na estrutura hierárquica do que as mulheres. A variável idade (beta $=-0,326$ ), entretanto, passa a explicar a variabilidade nos cargos ocupados pelos sujeitos inversamente, ou seja, sujeitos mais jovens tendem a ocupar cargos mais bem posicionados na hierarquia. N essa segunda análise de regressão, o método stepwise incluiu a variável idade em vez de tempo de serviço (variáveis fortemente correlacionadas) como variável com maior poder de explicação para a variabilidade nos cargos ocupados pelos sujeitos em 2003.

A terceira análise de regressão objetivou identificar a influência da quantidade de transferências de lugar na ocupação de cargos pelos sujeitos em 2003. A variável dependente é o cargo dos sujeitos em 2003 (cargo 
em 2003), e as independentes são o gênero (gênero), a idade (idade), o tempo de serviço (tempo de serviço) e o número de transferências de lugar de cada sujeito (mobilidade) em quatro recortes temporais: até 1995, ano em que foi implementado o PRC; até 1997, ano que corresponde ao Projeto 500; até 2000, ano que corresponde à segmentação de clientes; e até 2003. Descobrese então, pelos resultados ( $R^{2}$ ajustado $=0,379$; AN OVA: $F=11,389, g l=34, p<0,001)$, que o gênero continua explicando a variabilidade nos cargos ocupados pelos sujeitos, embora com menor intensidade ( $b e t a=0,286$ ), e que a variabilidade no número de transferências de lugar até 1995 - mobilidade até 95 (beta $=0,553$; $p<$ 0,001 ) - é a única dentre as mobilidades medidas (de 1995 a 2003) que explica, com significância estatística, a variabilidade nos cargos ocupados pelos sujeitos em 2003. As transferências de lugar ocorridas posteriormente ao PRC não explicam a ocupação dos grupos de cargos, demonstrando que a mobilidade dos sujeitos não significa mais ascensão correspondente de cargo, como geralmente acontecia antes do PRC. Tanto idade como tempo de serviço foram excluídas da análise de regressão pelo método stepwise, não havendo explicação adicional significativa para a variabilidade nos cargos ocupados pelos sujeitos em 2003.

Os resultados das análises de regressão demonstram que de 1995 a 2003 há mudanças no perfil dos sujeitos que ocupam os melhores grupos de cargos. Em 1995, homens com mais tempo de serviço ocupavam os mel hores grupos de cargos. Já em 2003, com a consolidação da reestruturação produtiva, homens mais joven s passam a ocu par os mel hores grupos de cargos. Além disso, devido à al ta correl ação entre idade e tempo de serviço $(r=0,933)$, a influência negativa da idade sobre o cargo em 2003 indica que as trajetórias dos sujeitos vêm sendo desval orizadas com a reestruturação produtiva do trabalho.

A seguir, apresentam-se três gráficos temporais comparativos dos índices de cargos médios ocupados pelos sujeitos $\left(\mathrm{CMS}_{\mathrm{t}}\right)$ segmentados por gênero, idade e tempo de serviço. Objetivou-se comparar o comportamento do $\mathrm{CMS}_{\mathrm{t}}$ dos distintos grupos ao longo do período 1990-2003 (veja as Figuras 3, 4 e 5).

A Figura 3 ilustra a diferença na ocupação dos grupos de cargos entre gêneros. Exceto no começo desta década, quando nem todos os sujeitos estavam presentes no cálculo do índice - pois vários ingressaram na empresa $X$ no decorrer do estudo -, os homens sempre ocuparam os cargos mais bem posicionados. Em agosto de 2003 essa diferença se acentua, cabendo às mulheres um CMS de 1,5000 e aos homens um CM S de 2,7619, o que os distancia em mais de uma posição hierárquica, em média. As análises de regressão mostram que, com a reestruturação produtiva, o gênero passa a explicar menos intensamente a variabilidade nos cargos ocupados pel os sujeitos. No entanto, a reestruturação manteve as mulheres em cargos menos bem posicionados em relação aos homens.

Figura 3 - Grupo de cargos médios (CMS $)$ por gênero.

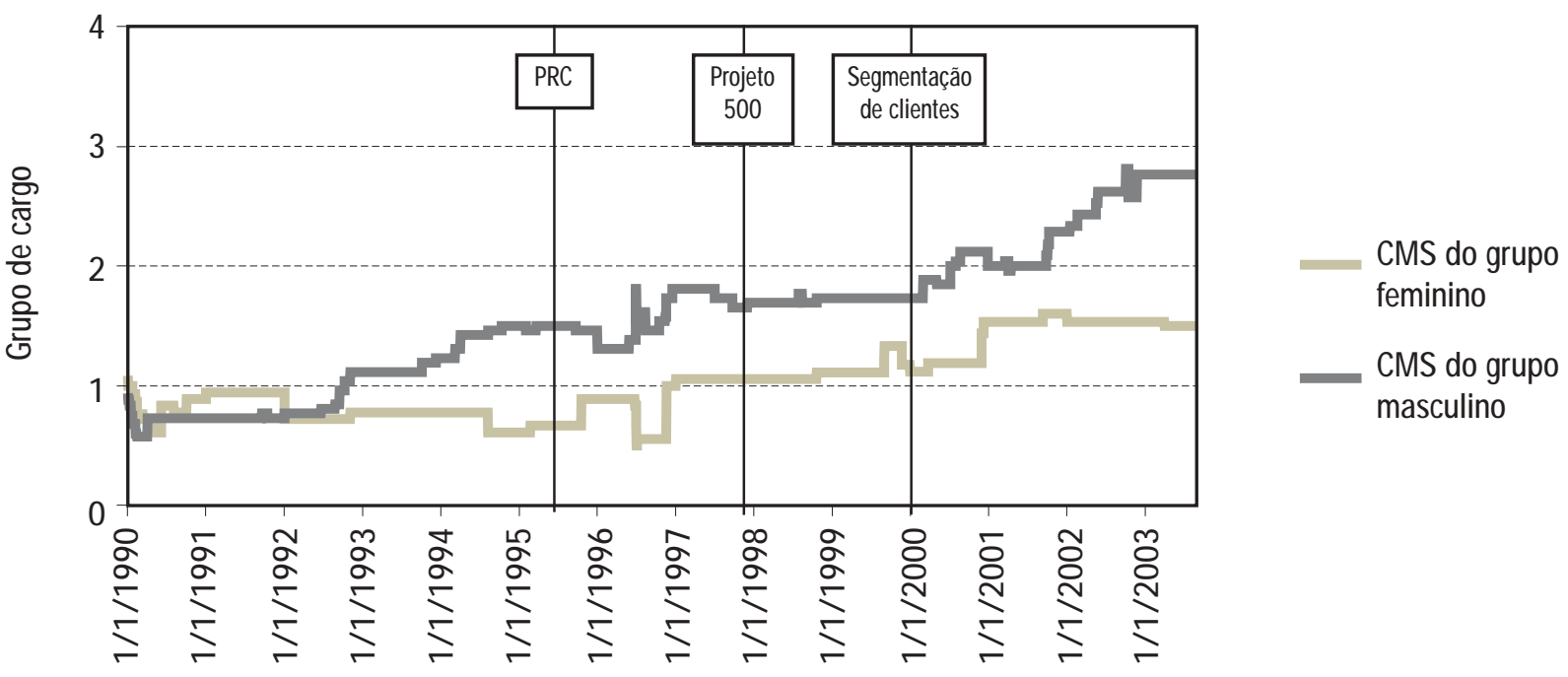


A Figura 4 mostra a trajetória de três grupos de sujeitos segmentados por idade ao longo do período 19902003: mais jovens, de 35 a 38 anos $(n=14)$, medianos, de 39 a 45 anos $(n=15)$ e mais velhos, de 46 a 58 anos $(n=15)$. Anteriormente ao PRC, os cargos médios que 0 primeiro, o segundo e o terceiro grupos ocupavam eram respectivamente $0,6429,0,4467$ e2,3333. Em 1996, como resultado da implementação do PRC, a ocupação dos grupos de cargos começa a se inverter, com os mais jo- vens ascendendo e os mais velhos descendendo na estrutura hierárquica. Posteriormente, em 2000, com a segmentação de clientes, o distanciamento começa a se tornar ainda mais visível. Em agosto de 2003, os cargos médios que o primeiro, o segundo e o terceiro grupos de idade ocupavam eram respectivamente 3,0000, 2,2308 e 1,4000. Evidencia-se, assim, que com a reestruturação produtiva os sujeitos mais velhos foram preteridos em relação aos mais novos na estrutura hierárquica.

Figura 4 - Grupo de cargos médios $\left(\mathrm{CMS}_{\mathrm{t}}\right)$ por idade.

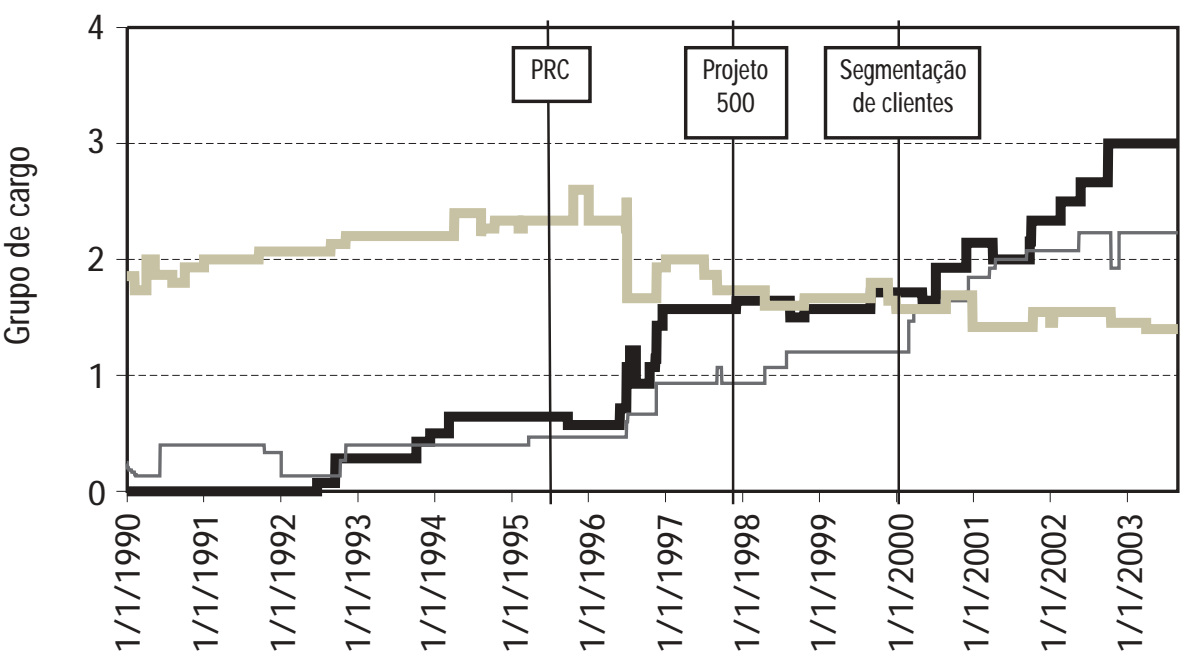

CMS do tercil de

35-38 anos de idade

CMS do tercil de 39-45 anos de idade

CMS do tercil de 46-58 anos de idade

Figura 5 - Grupo de cargos médios (CMS $)$ por antigüidade na empresa X.

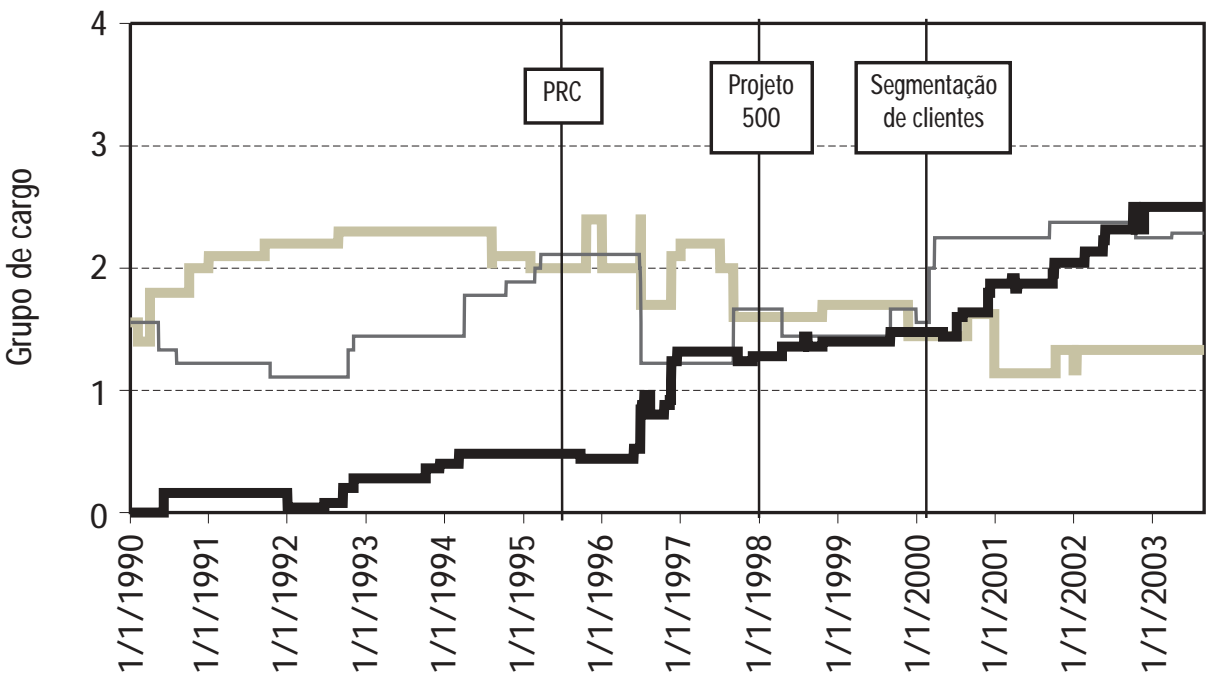

CMS do tercil de

25-30 anos de tempo de serviço

CMS do tercil de

19-24 anos de tempo de serviço

CMS do tercil de

13-18 anos de tempo de serviço 
Quadro 2 - Conseqüências humanas.

\section{INSTABILIDADE NA ESTABILIDADE DO EMPREGO}

A não linearidade na trajetória profissional leva à vivência de uma instabilidade na estabilidade, e à necessidade de garantir uma colocação a qualquer preço, uma vez que há um déficit de "lugares ocupáveis" (Castel, 1999) na estrutura da empresa. Ambas são conseqüências dos modos de experimentar 0 tempo permeado pela velocidade e pela urgência.

DESVALORIZAÇÃO DA TRAJETÓRIA DOS SUJEITOS NA NOVA LÓGICA ORGANIZACIONAL

Os efeitos mais perversos da reestruturação produtiva recaíram sobre os mais velhos e com mais tempo de serviço, pois estes descenderam na estrutura hierárquica da empresa. Ocorreu também o desligamento da empresa por meio dos PADVs ou de antecipação de aposentadoria, devido à pressão do cotidiano do trabalho, ou à pressão para a adesão.

"[...] tu não és gerente, tu estás gerente. É uma coisa perecível. Hoje tu estás, amanhã tu podes não estar". "[...] para conseguir uma situação financeira melhor, tu fazes um concurso e estás apto a assumir, e abre uma vaga lá na agência $X$, então tu vais. Não vais esperar abrir uma vaga por aqui. A primeira que abrir, tu vais".
"Muita pressão... para todo mundo, mas a gente via que era direcionada para os antigos". "Eles sabem que só faltam quatro anos para eu me aposentar, daí por que eles vão investir em mim?" "Nos dois últimos PADVs, o pessoal largou tudo, não agüentou a pressão, os desaforos e as humiIhações".

\section{RELACIONAMENTOS DE CURTO PRAZO E RUPTURA DOS LAÇOS DE CONFIANÇA}

Os vínculos de amizade, confiança e solidariedade que levam tempo para se formar fragilizavam-se com a imposição e intensificação da mobilidade. Ao impedir relacionamentos de longo prazo, a mobilidade impossibilita a manutenção e o surgimento de novos vínculos de amizade, confiança e solidariedade (Sennett, 2003). Há uma tentativa de manter os vínculos através de momentos festivos extra-empresa, mas esses são breves e, com o passar do tempo, tornam-se mais raros, até que se extinguem. Desse modo, fica inviabilizado que alguém seja testemunha de longo prazo da vida dos outros.

\section{NOMADISMO INVOLUNTÁRIO}

A perda de controle sobre 0 tempo e 0 trabalho mais a freqüente mobilidade para sobreviver dentro da nova lógica de instabilidade organizacional leva também à instabilidade nas relações pessoais e familiares, e à perda do controle da própria vida, 0 que coloca os sujeitos na condição de sujeitos "à deriva" como refere Sennett (2003).
"Cada um vai ali, fecha o seu (caixa), assina o ponto e vai embora, e 0 outro que se lixe. Não tem mais [...] Tem muita competitividade". "Antigamente a gente trabalhava com o guichê aberto, cada um mexia na gaveta do outro, nunca sumia um real. Hoje em dia, tu não confias nem na própria sombra em termos de dinheiro". "Por um tempo, (a relação) até continua quente, mas depois começa a esfriar. Se tem ainda algum contato, mas não é a mesma coisa".

\section{SOFRIMENTO PSIQQUICO}

Com a intensificação da mobilidade os sujeitos referem um agravamento do sofrimento psíquico que afeta a todos indiscriminadamente e que leva ao anestesiamento do corpo e da mente pelo uso de medicamentos antidepressivos e ansiolíticos, o que é considerado natural diante das pressões do cotidiano do trabalho. A disponibilidade constante e sem limites, diante das mudanças institucionais, não implica, necessariamente, vantagens para os sujeitos.
"A gente sempre procura, em qualquer movimento de função, adequar duas questões: 0 interesse da empresa e 0 interesse pessoal. Se der para fazer as duas juntas, excelente". "[...] quem reclamou do PRC, foram os gerentes, quem estava estabelecido na época. Esses ficaram $p$. da vida. Esses que perderam a função tiveram que recomeçar do zero". "Aí me caiu a ficha: daqui a pouco vão me trocar tudo de novo".

"[...] agora me trato com psiquiatra uma vez por semana, tomo antidepressivo. Se tu conversares com $50 \%$ da empresa, dos gerentes e qualquer um outro toma antidepressivo, porque senão tu não agüentas a pressão [...]. Tinha uma colega minha que dizia 'vai tomar um antidepressivo. Não adianta tu dares murro em ponta de faca. Tu tens que aceitar as mudanças que estão vindo'. Tem gente que não conta, que não diz". "Tinha que ser uma coisa compensadora, que valesse a pena. Para tu teres um transtorno tão grande, para fazeres uma mudança tão radical de vida". 
Devido à al ta correlação entre idade e tempo de serviço, a Figura 5 repete o padrão da Figura 4, como era de se esperar. Evidencia-se a ocorrência de uma inversão de posições entre o grupo com mais tempo de serviço e o grupo com menos tempo de serviço na empresa. Esse fenômeno ocorre como resultado da impl ementação do PRC, quando o grupo com menos tempo de serviço ascende intensamente e o grupo com mais tempo de serviço descende. Ao final de 2003, o grupo com mais tempo de serviço apresentava um CM S de 1,3333, enquanto o grupo com menos tempo de serviço apresentava um CM S de 2,5000. A reestruturação produtiva parece ter desvalorizado a trajetória dos sujeitos.

\section{Nomadismo involuntário: conseqüências humanas da mobilidade na reestruturação do trabalho bancário}

As conseqüências humanas da mobilidade advinda da reestruturação produtiva se relacionam à exigência de um novo modo de ser bancário que, diante de sua inevitabilidade, aos poucos é incorporada pelos sujeitos. Entre as principais conseqüências, encontramse a instabilidade na estabilidade do emprego, a desval orização das trajetórias dos sujeitos na empresa, os relacionamentos de curto prazo, o nomadismo invoI untário e o sofrimento psíquico, conforme apresentadas no Quadro 2.

\section{CONSIDERAÇÕES FINAIS}

Enquanto produto do trabal ho imaterial que se encontra na interface dessa nova relação produção-consumo (Lazzarato e N egri, 2001), pode-se dizer que a mobilidade resultante da reestruturação produtiva do trabaIho bancário está intimamente relacionada aos novos modos de gestão voltados para dentro e para fora da empresa. Os modos de gestão não se restringem aos sujeitos da reestruturação do trabalho bancário, atingindo, igual mente, aqueles com quem se relacionam.

A empresa $X$ vem promovendo incessantes mudanças com o objetivo de se adaptar ao cenário de agilidade, informatização e trabal ho imaterial requeridos pelo mercado. Mobilidade sempre existiu na empresa X. No entanto, com a reestruturação produtiva, depois do PRC, em 1995, ela passou a ser mais freqüente, mais veloz, oscilante e com implicações mais severas para os sujeitos.

N ota-se por parte do capital a necessidade de implantação, nos sujeitos do trabalho, de uma total disponibilidade ao trabalho e às instituições, cerceando os mo- dos de resistência via gestão de pessoas. Desse modo, a subjetividade a ser assumida e vivida cotidianamente abrange não só as relações que se estabelecem dos sujeitos consigo mesmos, mas também as relações com aquel es que os rodeiam. Essa lógica de competitividade mercadológica que se instala no cotidiano organizacional é caracterizada pelos altos índices de desemprego no setor e passa a ser incorporada de tal modo pelos bancários, que resulta no consentimento com relação à mobilidade, e o conseqüente sofrimento psíquico.

Para tanto, entre outras possibilidades, o sujeito labiríntico, conforme refere Bauman (2001), dispõese a viver fora do espaço e do tempo, pois tem acopladas em si as mais recentes próteses tecnológicas, e, mesmo sem indicação de direção ou de duração, segue a viagem. Trata-se de um sujeito que, entre outras denominações, poderia ser chamado de surfista, cuja característica mais desejável e notável é saber compor com as instabilidades e incertezas, e continuar deslizando leve e vel oz sobre uma superfície fluida, inconstante, não aderente. Trata-se igual mente de um sujeito que se poderia chamar camal eônico, "deslocável ao sabor do mercado", adaptável "aos tais tempos que correm" (Guattari e Rolnik, 1996, p. 39).

Desse modo, em face das conseqüências humanas apresentadas, pede-se ao sujeito da reestruturação produtiva do trabal ho bancário um estilo de vida ou modo de existência que o constitua como sujeito da velocidade, do deslocamento e do desapego a lugares, pessoas e modos de agir e de ser. 0 nomadismo involuntário pode, portanto, ser tomado como uma das expressões da intensificação das experiências de ruptura que caracterizam o trabalho em reestruturação.

\section{REFERÊNCIAS BIBLIOGRÁFICAS}

BAUMAN, Z. M odernidade líquida. Rio de Janeiro: Zahar, 2001.

BESSI, V.; GRISCI, C. L. I. Daqui pra frente vai ter de ser diferente: Programa de Apoio à Demissão Voluntária em tempos de reestruturação produtiva do trabalho bancário. In: ENCONTRO NACIONAL DA ASSOCIAÇÃO NACIONAL DOS PROGRAMAS DE PÓS-GRADUAÇÃO E PESQUISA EM ADMINISTRAÇÃO, 27, 2003, Atibaia. Anais. Atibaia: ANPAD, 2003.

CASTEL, R. As metamorfoses da questão social: crônica do salário. Petrópolis: Vozes, 1998.

CASTELLS, M. A sociedade em rede. São Paulo: Paz e Terra, 1999.

CHESN AIS, F. A mundialização financeira: gênese, custos e riscos. São Paulo: Xamã, 1998. 
COCCO, G. Trabalho e cidadania: produção e direitos na era da globalização. São Paulo: Cortez, 2000.

DELEUZE, G. Conversações: 1972-1990. Rio de Janeiro: Ed. 34, 1998.

DIEESE. Conjuntura, resultados, remuneração e empregos: subsídios para discussão na 3a Conferência Nacional dos Trabalhadores do Ramo Financeiro. Elaborado pelo Dieese - Linha Bancários. São Paulo: Dieese, 2001.

DUPAS, G. Ética e poder na sociedade da informação. São Paulo: Unesp, 2000.

GRISCI, C. L. I. Dos corpos em rede às maquinas em rede: reestruturação do trabalho bancário e constituição do sujeito. Revista de Administração Contemporânea, v. 7, n. 1, p. 9-35, 2003.

GUATTARI, F.; ROLNIK, S. Micropolítica: cartografias do desejo. 4. ed. Petrópolis: Vozes, 1996.

HARVEY, D. Condição pós-moderna: uma pesquisa sobre as origens da mudança social. 2.ed. São Paulo: Loyola, 1993.
LAZZARATO, M.; NEGRI, A. Trabalho imaterial: formas de vida e produção de subjetividade. Rio de Janeiro: DP\&A, 2001.

MINAYO, M. (Org.); DESLANDES, S.; CRUZ NETO, O.; GOMES, R. Pesquisa social: teoria, método e criatividade. Petrópolis: Vozes, 1994.

PELBART, P. A vertigem por um fio: políticas da subjetividade contemporânea. São Paulo: Iluminuras/Fapesp, 2000.

ROESCH, S. Projetos de estágio e de pesquisa em administração: guia para estágios, trabalhos de conclusão, dissertação e estudos de caso. 2. ed., São PauIo: Atlas, 1999.

SEN NETT, R. A corrosão do caráter: conseqüências pessoais do trabalho no novo capitalismo. Rio de Janeiro: Record, 2003.

VIRILIO, P. Velocidade e política. São Paulo: Estação Liberdade, 1996.

YIN, R. K. Estudo de caso: planejamento e métodos. Porto Alegre: Bookman, 2001.

\section{Artigo recebido em 15.04.2004. Aprovado em 14.09.2005.}

\section{C armem Ligia lochins G risci}

Professora da UFRGS. Doutora em Psicologia pela PUC-RS.

Interesses de pesquisa nas áreas de trabalho, gestão e subjetividade: trabal ho imaterial, espaço-

temporalidade, controle, gênero e sofrimento psíquico.

E-mail: cligrisci@ea.ufrgs.br

Endereço: Av. Washington Luís, 855, Centro, Porto Alegre - RS, 90010-460.

\section{Gilles C hemale Cigerza}

Graduando em Administração de Empresas na UFRGS e bolsista de iniciação de pesquisa/CN Pq. Interesses de pesquisa nas áreas de trabalho, gestão e subjetividade: trabal ho imaterial, espaçotemporalidade, controle, gênero e sofrimento psíquico.

E-mail: gillescigerza@hotmail.com

Endereço: Av. Washington Luís, 855, Centro, Porto Alegre - RS, 90010-460.

\section{Pedro Mendes Hofmeister}

Graduando em Administração de Empresas naUFRGS e bolsista de iniciação de pesquisa/F apergs. Interesses de pesquisa nas áreas de trabal ho, gestão e subjetividade: trabal ho imaterial, espaçotemporalidade, controle, gênero e sofrimento psíquico.

E-mail: pedromh@gmail.com

Endereço: Av. Washington Luís, 855, Centro, Porto Alegre - RS, 90010-460.

\section{João Luiz Becker}

Professor da UFRGS. Doutor em Administração pela University of Califórnia at Los Angeles. Interesses de pesquisa nas áreas de sistemas de informação e apoio à decisão, pesquisa operacional e métodos quantitativos.

E-mail: jlbecker@ea.ufrgs.br

Endereço: Av. Washington Luís, 855, Centro, Porto Alegre - RS, 90010-460. 